Global Increases in Individualism

\author{
Henri C. Santos ${ }^{1}$ \\ Michael E. W. Varnum ${ }^{2}$ \\ Igor Grossmann ${ }^{1}$ \\ ${ }^{1}$ University of Waterloo, Canada \\ ${ }^{2}$ Arizona State University, USA
}

In press, Psychological Science

Correspondence concerning this article should be addressed to Henri Santos, Department of

Psychology, University of Waterloo, 200 University Avenue West, Waterloo, Ontario, Canada

N2L 3G1. Contact: hsantos@ uwaterloo.ca or Igor Grossmann, Department of Psychology, University of Waterloo, 200 University Avenue West, Waterloo, Ontario, Canada N2L 3G1.

Contact: 1grossma@uwaterloo.ca

This article may not exactly replicate the final version published in the journal. It is not the copy of record. 


\begin{abstract}
Individualism appears to have increased over the past several decades, yet most research documenting this shift has been limited to the study of a handful of highly-developed countries. Is the world becoming more individualistic as a whole? If so, why? To address these questions, here we examine 51 years of data on individualistic practices and values across 77 countries. Our findings suggest that individualism is indeed rising in most of societies we tested. Despite dramatic shifts towards greater individualism around the world, cultural differences remain sizeable. Moreover, cultural differences are primarily linked to changes in socioeconomic development, and to a lesser extent to shifts in pathogen prevalence, disaster frequency, and climatic stress.
\end{abstract}

Keywords: cultural change, individualism, cross-cultural differences, social ecology, change over time 


\section{Global Increases in Individualism}

In the last century, some affluent societies have been moving toward greater individualism in values and practices. Has individualism risen around the globe or is such shift limited to a few highly-developed societies? Why have such shifts occurred? Utilizing 51 years of data on individualistic practices and values from 77 countries, we present novel empirical evidence regarding the universality and potential causes of cultural shifts and reflect on outstanding questions for future research.

\section{Cross-Cultural Differences in Individualism and Collectivism}

Individualism-collectivism (IC) is currently the most discussed construct in cross-cultural studies. Since the seminal works by Triandis (1995), Hofstede (2001), and Markus and Kitayama (1991), researchers have used this cultural dimension to explain variations in psychological processes across different cultural groups. Individualism promotes a view of the self as selfdirected, autonomous, and separate from others. Conversely, collectivism fosters an interconnected view of the self that overlaps with close others, with individuals' thoughts, feelings, and behaviors embedded in social contexts (Markus \& Kitayama, 1991; Triandis, 1995; Varnum, Grossmann, Kitayama, \& Nisbett, 2010). Individualistic cultures prioritize independence and uniqueness, whereas collectivistic cultures emphasize family ties and fitting in (Grossmann \& Na, 2014). Cross-cultural differences in IC occur when examining values and norms (e.g., obedience; Hofstede, 2001), socialization practices (Greenfield, 2009) and cultural products (Morling \& Lamoreaux, 2008). 


\section{Cross-Temporal Shifts in Individualism-Collectivism}

Cultural values and practices are not static in society (Kashima, 2014; Morris, Chiu, \& Liu, 2015). Recently, scholars have begun to explore how IC may change over time (e.g., Greenfield, 2009; Grossmann \& Varnum, 2015; Kitayama, Conway, Pietromonaco, Park, \& Plaut, 2010; Twenge, Dawson, \& Campbell, 2016). Initial studies tracked changes between 1969 and 1991 in Mayan communities (Greenfield, 2009). During this period, this group's economy shifted from a subsistence to a market-based economy, and this change was associated with a learning environment that became more individualistic. More recently, researchers have analyzed several decades of US survey data to assess potential changes in IC-related constructs. For instance, Twenge and colleagues (Twenge, Campbell, \& Gentile, 2012) found increases in the better-than-average effect among college students from 1966 to 2009.

Subsequent studies have shown shifts in individualism in cultural products and practices: Americans and Japanese have become increasingly likely to give their children relatively unique names (Grossmann \& Varnum, 2015; Ogihara et al., 2015; Twenge et al., 2016). Also, Americans have become less likely to live in multigenerational households and more likely to divorce (Grossmann \& Varnum, 2015). Moreover, the frequencies of words reflecting individualist themes (e.g., self, unique, personal, "me"/ "mine") vs. collectivistic ones (e.g., obedience, belong, together, "we"/ "ours") have increased over time in books from the U.S. (Greenfield, 2013; Grossmann \& Varnum, 2015) and several other countries (e.g., Zeng \& Greenfield, 2015; Yu et al., 2016).

At least three studies have explored changes in markers of IC across societies. Using data from the World Values Surveys, Inglehart and Baker (2000) found increasing self-expression (a concept related to individualism; Inglehart \& Oyserman, 2004) across 65 countries. Consistent 
with this idea, Yu and colleagues (2016) found increasing use of "me"/“mine" in eight language groups over a span of 59 years. Further, Hamamura's (2012) analysis of survey and census data from the U.S. and Japan revealed shifts towards more individualistic relational practices in both countries. These studies suggest that there may be a global trend towards individualism. However, much of this data came from developed countries, limiting inferences about less economically-developed countries. And although Inglehart and Baker (2000) observed how countries that experienced economic development endorsed more individualistic values, they did not examine changes in practices, nor did they systematically test multiple hypotheses for why individualistic values and practices may be on the rise.

\section{Changes in Ecology and Changes in IC}

Recently, scholars studying cross-cultural variation have begun using an ecological framework to explain cross-cultural differences (Oishi \& Graham, 2010; Thornhill \& Fincher, 2014; Van de Vliert, 2013). This research has focused on dimensions of ecological affordance and threat, including socioeconomic development, frequency of natural disasters, pathogen prevalence, and climatic stress.

Socioeconomic development. Several scholars have theorized that individualism-related changes are explained by socioeconomic development, which involves a shift from agricultural to industrial and post-industrial economies, greater occupational prestige and education, and higher income (e.g., Inglehart \& Baker, 2000; Kağıtçıbaşı, 2007; Kraus, Piff, Mendoza-Denton, Rheinschmidt, \& Keltner, 2012; Newson \& Richerson, 2009; Triandis, 1995; Varnum et al., 2010). Living in an economically developed society reduces the need to rely on a group for survival, allowing people to prioritize individual goals and personal freedom (Inglehart \& Baker, 2000). A related argument specifically focuses on the rise of urban centers, holding that city 
environments promote individualism (Greenfield, 2009; Yamagishi, Hashimoto, Li, \& Schug, 2012). Although there are different explanations for modernization, correlational studies across multiple countries (e.g., Hofstede, 2001; Kashima \& Kashima, 2003) and observations of single communities before and after economic development (Greenfield, 2009) support the claim that more developed and urbanized societies are more individualistic. Also, time-lagged analyses in the U.S. showed that over 150 years, shifts from blue-collar to white-collar jobs preceded changes in individualistic living arrangements, cultural products, and practices (Grossmann \& Varnum, 2015).

Disaster frequency. Environmental threats could also shape culture. Triandis (2009) proposed that more frequent disasters would reduce individuals' sense of agency, which would then lead to less individualism. However, research on reactions to trauma and the cognitive effects of stress suggest that the experience of a disaster would narrow attentional scope (Wachtel, 1968) - a tendency that frequently accompanies individualism (Varnum et al., 2010). Thus, it is possible that more frequent disasters may lead to greater individualism. Consistent with the latter view, increases in individualistic practices were preceded by increases in disaster frequency in the US (Grossmann \& Varnum, 2015).

Pathogen prevalence. Evolutionary theorists argue that humans have developed a behavioral immune system (Schaller \& Park, 2011), a suite of cognitive-behavioral tendencies including collectivism - that reduce disease transmission. Collectivism limits people's contact outside the in-group, reducing the likelihood of acquiring infections (Thornhill \& Fincher, 2014). Further, people who live in regions with many infectious diseases are more likely to emphasize obedience and conformity over individualistic values like self-reliance, which, all else being equal, likely reduces the chance of infection (Murray, Trudeau, \& Schaller, 2011). While many 
of these studies have examined the correlations between historical pathogen prevalence and contemporary data on IC-related variables, only one US-based study has investigated this relationship over time (Grossmann \& Varnum, 2015).

Climate. People living in climates that deviate from the optimal level (22 Celsius/72 Fahrenheit; cf. Van de Vliert, 2013) face greater environmental stresses. These stresses may increase focus on survival goals and in-group support as opposed to individualistic pursuits like self-expression (Hofstede, 2001; Kashima \& Kashima, 2003; Van de Vliert, 2013). Notably, the effects of suboptimal climates are particularly felt in countries that do not have the financial resources to cope with them. According to this climato-economic theory, increased climatic stress should lead to greater individualism in richer countries, but a shift toward collectivism in poorer countries (Van de Vliert, 2013).

\section{The Current Research}

We performed a formal analysis of change over 51 years in a subset of individualistic practices and values across 77 countries, which varied in their economic development (e.g., highly-developed Switzerland vs. less-developed Malawi) and geographic diversity. To assess whether the rise in individualism is a global phenomenon, we extended previous work on changes in IC that was conducted in a few industrialized countries (Greenfield, 2013; Grossmann \& Varnum, 2015; Hamamura, 2012; Zeng \& Greenfield, 2015) to a more representative sample of societies. We also examined how certain socio-ecological factors - socioeconomic development, disaster frequency, pathogen prevalence and climatic-stress - account for pancultural IC shifts. 


\section{Methods}

We focused on behavioral choices resulting in individualist vs. collectivist practices (e.g., living alone vs. living together with grandparents; Triandis, 1995) and values associated with individualism (e.g., valuing independence; Hamamura, 2012). In line with previous research (Grossmann \& Na, 2014; Hofstede, 2001), we conceptualized cultural-level changes in individualism vs. collectivism as a single country-level dimension, acknowledging that individualism and collectivism may be independent from each other when explored on the individual level of analysis (Grossmann \& Na, 2014; Schimmack, Oishi, \& Diener, 2005; Triandis, 1995).

\section{Country Selection}

Table 1 shows all countries used in the analyses and the source of their data. For the analysis of individualistic practices, we selected 41 countries that had at least three data points of national census data (i.e. covering at least two decades between 1960 and 2011, as most census data is collected every 10 years). We retrieved this data from the Integrated Public Use Microdata Series, International database (IPUMS; see Supplemental Table S1 for a full list of databases used) which standardized measures such that indicators can be easily compared to each other regardless of the source country or survey. For the analysis of individualistic values, we selected 52 countries that had at least three data points over 10 years in the World Values Survey and European Values Survey integrated database (WVS). We chose a shorter range of time since the WVS was collected in more frequent waves. Of these countries, 16 were also part of the countries used for individualistic practices. 
Table 1.

List of Countries in the IPUMS and WVS Samples.

\begin{tabular}{ccccc}
\hline \multicolumn{2}{c}{ IPUMS alone } & IPUMS and WVS & \multicolumn{2}{c}{ WVS alone } \\
\hline Bangladesh & Israel & Argentina & Albania & Lithuania \\
Bolivia & Kenya & Austria & Armenia & Macedonia \\
Brazil & Malawi & Canada & Australia & Malta \\
Burkina Faso & Malaysia & Chile & Azerbaijan & Moldova \\
Cameroon & Mali & France & Belarus & Netherlands \\
Colombia & Nicaragua & Hungary & Belgium & New Zealand \\
Costa Rica & Panama & India & Bulgaria & Nigeria \\
Dominican Republic & Puerto Rico & Ireland & China & Norway \\
Ecuador & Thailand & Mexico & Croatia & Peru \\
Fiji & Venezuela & Morocco & Czech Republic & Poland \\
Greece & Vietnam & Portugal & Denmark & Russian Federation \\
Haiti & Zambia & Romania & Estonia & Slovenia \\
Indonesia & & Spain & Finland & South Africa \\
& & Georgia & South Korea \\
& & Unitzerland & Germany & Sweden \\
& & Uruguay & Iceland & Turkey \\
& & Italy & Ukraine \\
& & Japan & United Kingdom \\
\hline
\end{tabular}

\section{Socio-Ecological Factors}

Socioeconomic development. We examined markers of socioeconomic development that should be associated with differences in individualism: shifts from agriculture to a service economy, occupational prestige, educational attainment, income, urbanization (Greenfield, 2009; Grossmann \& Varnum, 2015; Inglehart \& Baker, 2000; Kraus et al., 2012).

White-collar vs. agricultural jobs. We examined whether people had white-collar jobs (i.e., more developed) or agricultural jobs (i.e., less developed; Greenfield, 2009). Using harmonized census data from IPUMS, we took the percentage of people with occupations classified as "skilled agricultural, forestry, and fishery workers" as a measure of agricultural jobs. We also took the percentage of people with occupations classified as "legislators, senior officials, and managers," "professionals," "technicians and associate professionals," "clerks," 
and "service workers and shop and market sales" as a measure of white-collar jobs. We then computed the difference between the percentages of agriculture jobs from those of white-collar jobs, such that higher scores represent more white-collar jobs in society.

Occupational prestige. We obtained occupation data coded by IPUMS into the major categories in the 1988 International Standard Classification of Occupations scheme. We weighted these categories using the 1996 Standard International Occupational Prestige Scale, which reflects popular evaluation of occupational standing across multiple countries. Higher scores indicate jobs with greater prestige.

Educational attainment. We used harmonized census data on educational attainment that was already recorded in the IPUMS database using a standard, 4-point scale (1 - less than primary completed to 4 - university completed).

Income. We used gross domestic product (GDP) as an indicator of income. Following recommendations by Deaton (2008), we log transformed the GDP per capita (current US\$) from the World Bank database.

Urbanization. Using the same harmonized census data, we calculated the percentage of households coded as urban.

These variables were correlated to each other in the expected direction, $.17<|\tau| \mathrm{s}<.74$ (see Supplementary Table S2). To simplify these data, we computed a composite score of individualistic socioeconomic development by standardizing and getting the mean of agriculture vs. white-collar jobs, occupational prestige, educational attainment, income, and urbanization. To account for missing data when computing the composite score, we used linear interpolation between any two data points, which were no more than ten years apart (we had income data for almost every year in the sample, and thus no interpolation was necessary for this variable). 
Countries in the IPUMS countries included measures of agriculture vs. white-collar jobs, occupational prestige, educational attainment, and urbanization. For the other countries, we used the standardized income data. The findings were similar with and without the countries that only had income data (see Supplementary Analyses).

Disaster frequency. We obtained data on disaster prevalence from 1960 to the present from the International Disaster Database, maintained by the Centre for Research on the Epidemiology of Disasters in Belgium. Disasters were classified as natural (e.g., earthquakes, storms, floods) or technological (e.g., fire, chemical spill, transportation accidents) events where at least one of the following criteria was met: 10 or more people dead, 100 or more people affected, declaration of a state of emergency, or call for international assistance. We logtransformed these values to address issues of skew and kurtosis.

Pathogen prevalence. We obtained annual data on the incidence of infectious diseases from the Global Health Observatory data repository. We selected 7 diseases that had data spanning at least 20 years: cholera, diphtheria, measles, neonatal tetanus, pertussis, total tetanus, and tuberculosis. To estimate the prevalence of these diseases, we divided the number of incidences of each disease by the total annual population, taken from the World Bank database. We then took the sum of all of these ratios as an overall measure of the prevalence of infectious pathogens.

Climate. We obtained the monthly mean temperature for each country from the Climate Change Knowledge Portal database. These data were obtained from thousands of weather stations all throughout the world and should represent the average climate across the whole country. We then calculated the annual mean from this data and took the absolute value of the 
difference between the annual mean and $22 \mathrm{C}$ as a measure of the deviation from the optimal temperature for humans (Van de Vliert, 2013).

\section{Individualism-Collectivism}

Practices. Previous work has examined shifts in individualism by looking at changes in choices people make concerning their living arrangements. Individualistic people are more likely to have smaller households, live alone, less likely to personally care for their parents and grandparents by living with them, and more likely to be divorced (Grossmann \& Varnum, 2015; Triandis, 1995; Vandello \& Cohen, 1999). To measure these behaviors, we analyzed harmonized census data from IPUMS.

Household size. We obtained the mean number of relatives (by blood, marriage, or adoption) in the household. Individualistic families would be more likely to live alone and have smaller households, so we reverse-scored this measure.

Living alone. We calculated the percentage of households that only had one member. We expected this percentage to be higher in more individualistic countries.

Older adults living alone. We calculated the percentage of single-member households with members aged 60 or older. We also expected this to be higher in more individualistic countries.

Divorce. We calculated the percentage of people who were divorced or separated as opposed to married or widowed. We also expected this to be higher in more individualistic countries.

These variables were correlated to each other in the expected direction, $.27<|\tau| \mathrm{s}<.69$, with the exception of older adults living alone and divorce, $\tau=.02$ (see Supplementary Table S3). Therefore, after pooling all measures such that higher values indicate greater individualism, 
they were standardized across all years and countries with available data. The mean of these standardized values was computed as an annual measure of individualistic practices. Notably, tests without divorce as part of the IC composite yielded similar results to those reported below (see Supplementary Analyses). We also looked at the number of children born, single-child families, and married couples with no children as part of the individualism index, but since these variables are closely related to life history strategies, we did not include them in the main analysis. We found similar findings with these variables in the composite (see Supplementary Analyses).

Values. Aside from changes in practices, culture is also manifested in the values held by a country. We used the following three items from the World Values Survey that have been used as indices of individualism-collectivism in prior cross-cultural research and have been linked to established self-report and non-self-report measures of individualism-collectivism (Hamamura, 2012; Inglehart \& Oyserman, 2004).

Importance of friends vs. family. Respondents answered two four-point items asking them about the importance of their friends and their family (1 - very important to 4 - not very important). The scales were reverse scored so that higher mean scores indicated greater value given to friends and family. We then subtracted the score for friends from the one of family, so that this difference represents the importance of friendship relative to family. Higher scores on this measure reflect a lower relative emphasis on the family, which is associated with less collectivism (Hamamura, 2012; Triandis, 1995).

Independent children. We calculated the percentage of respondents who said that it was important to teach the value of independence to their children (dichotomous yes/no measure). 
Individualistic societies socialize children to be more independent, in contrast to collectivistic societies, which put greater emphasis on obedience (Hamamura, 2012; Triandis, 1995).

Preference for self-expression. Respondents were asked to think about their country's goals in the future and select two out of the four goals that would be important to them. If they picked at least one self-expression goal (i.e., "Giving people more say in important government decisions" or "Protecting freedom of speech"), they were coded as valuing self-expression, which is nomologically linked to the notion of individualism (Inglehart \& Oyserman, 2004).

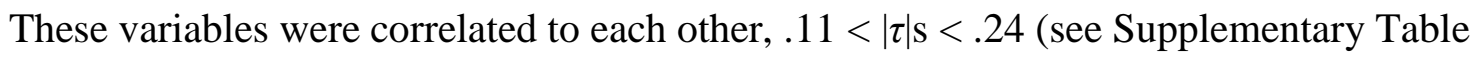
S4). After pooling variables to be in the same direction, a composite score of individualistic values was computed by standardizing values for each year across all countries and then getting their mean.

\section{Data Analysis}

We performed all analyses in the R language for statistical computing (see Supplementary Table S1 for a list of the main R packages used). To reproduce all results, see publicly available code and data at osf.io/au4x3. We computed two averaged index scores out of multiple measures: individualistic practices and values. To allow the computation of composite scores, we standardized all of our individualism and socioeconomic development variables before analysis. We calculated z-scores using the grand means and standard deviations taken across all years and countries in the sample (as opposed to calculating them within each country or year), since we were interested in countries' level of individualism and socioeconomic development relative to other countries and time periods overall (Hox, 2002). Following recommendations for longitudinal analyses, we set the first time point to zero. 
We performed multilevel modeling (MLM) with the lme4 and lmerTest packages for R, because differences between countries explained a significant part of the variance in individualism $-54 \%$ for practices and $30 \%$ for values (intra-class correlations are .73 and .54 , respectively). This variance pattern necessitates the use of MLM to control for these differences (Hox, 2002).

We nested data per year within countries and treated the proposed predictors as fixed effects, controlling for differences between countries (i.e. random effects; Hox, 2002). Since we expected countries to vary in their starting values, we allowed the intercepts to be random in our analyses. Similar to other statistical programs (e.g., SPSS, SAS), we estimate statistical significance using the Satterthwaite approximation for denominator degrees of freedom. To estimate the relative effect size of main effects, we chose to use marginal R-squared values $\left(R^{2}{ }_{m}\right)$, which estimates the proportion of residual variance explained by the predictors only (i.e., irrespective of the variance explained by between-country differences; Nakagawa $\&$ Schielzeth, 2013), using the MuMIn package for R.

Notably, caution should be taken when estimating the R-squared term of interactions between two variables in a multi-level models. This is because the marginal R-squared estimation for multi-level models does not estimate the effect size of the interaction term per se. Rather, it estimates the effect size of the whole model, which includes the main effects. Therefore, to clarify the incremental effect of the interaction term, we reported Akaike Information Criterion (AIC) which allows for exact model comparisons (Hox, 2002). For AIC, lower scores indicate a better model. We calculated the change in AIC ( $\triangle \mathrm{AIC})$ by subtracting the AIC of the model with the interaction effect from the model with only main effects. An $\Delta$ AIC $>$ 
2 would indicate that the interaction model is a superior model (i.e. it explains additional variance as compared to a model with main effects alone).

\section{Results}

\section{Change in Individualism over Time}

We performed formal modeling of the rate of individualism changes over time, by adding year as a predictor in the model. In support of our first hypothesis, we observed increased individualism over time both in terms of both practices, $B=0.02, S E=0.001, t(142.03)=13.54$, $p<.001, R^{2}{ }_{m}=.12$, and values, $B=0.03, S E=0.004, t(191.88)=9.76, p<.001, R^{2}{ }_{m}=.12$, suggesting that since 1960, individualism has increased by about 12 percent worldwide.

Supplementary regional and country-specific analyses indicated that individualism has been on a rise across all regions and in most of the countries we examined (see Supplementary Table S5). For cultural practices, only four countries (Cameroon, Malawi, Malaysia, and Mali ) showed a non-negligible reversal in the direction of change, whereas 34 out of 41 countries exhibited a substantial change in the predicted direction (see Figure 1 and Supplementary Table S6). For values, only five countries (Armenia, China, Croatia, Ukraine, and Uruguay) showed a non-negligible reversal in the direction of change, whereas 37 out of 51 countries exhibited a substantial change in the predicted direction (see Figure 2 and Supplementary Table S7). We consider possible reasons why this handful of countries showed a different trend then the rest of the world in the discussion. In summary, overall we observed increasing individualism in the vast majority of sampled countries. Notably, despite dramatic shifts towards greater individualism around the world, Figures 1 and 2 indicate that cultural differences remain sizeable up to this day. 


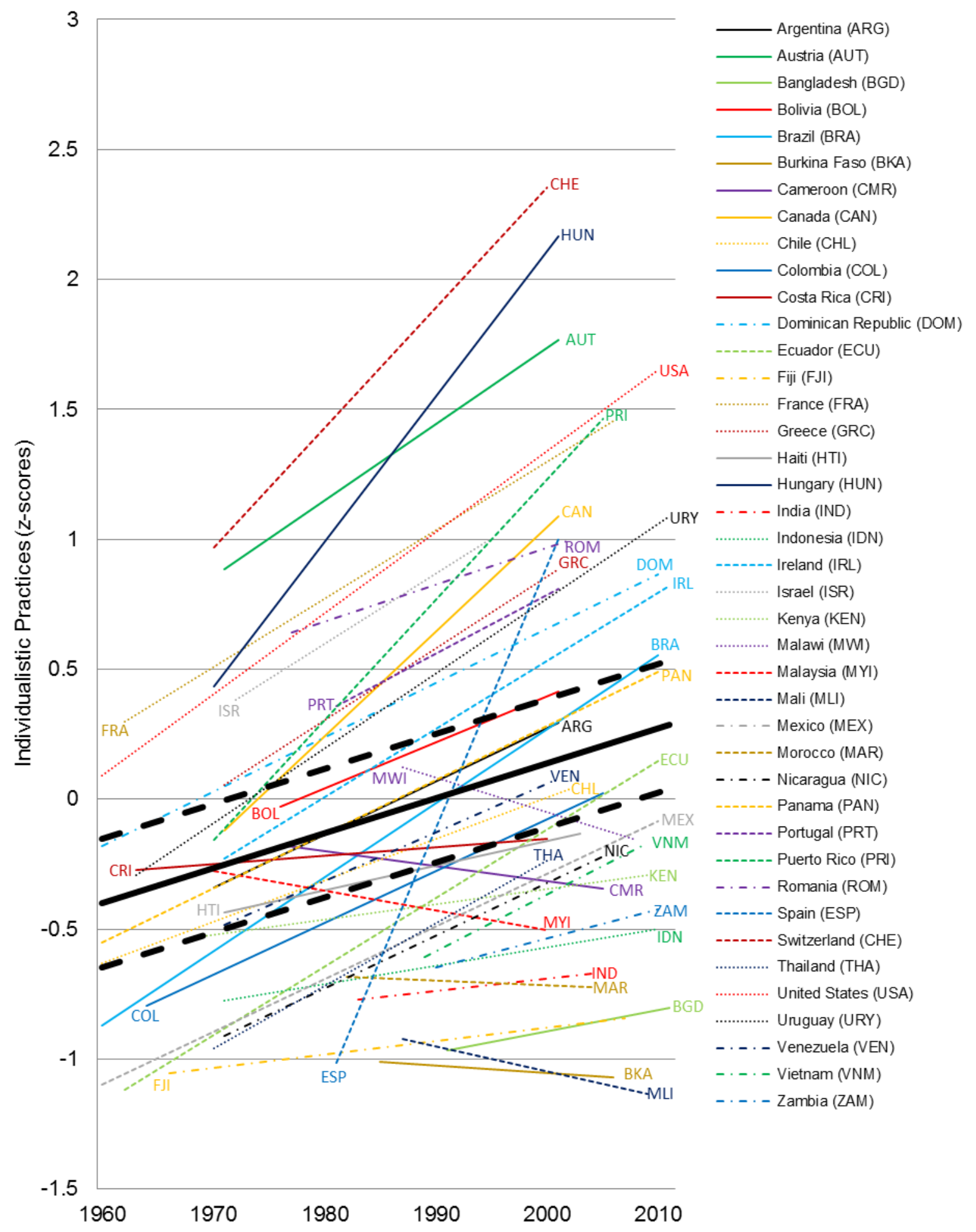

Fig. 1.

Change in Individualistic Practices over Time. For each country, lines are drawn between the first and last data points for individualism (standardized). The bold black line represents the line of best fit across all data points and the bold dashed lines represent $95 \%$ confidence intervals. 

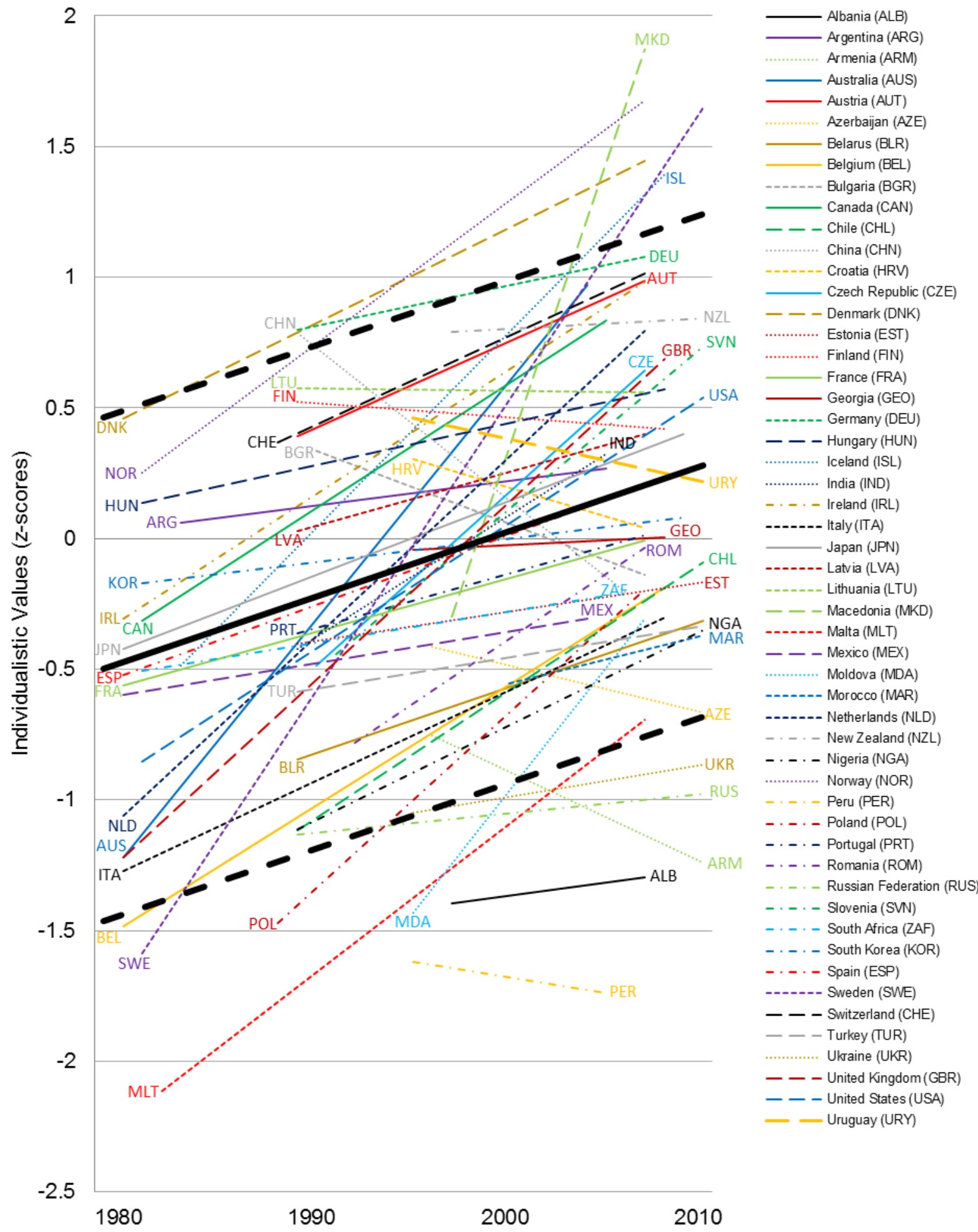

Fig. 2.

Change in Individualistic Values over Time. For each country, lines are drawn between the first and last data points for individualism (standardized). The bold black line represents the line of best fit across all data points and the bold dashed lines represent 95\% confidence intervals. 


\section{Predictors of Change in Individualism}

Next, we examined how socio-ecological changes impacted shifts in individualism. Prior work (e.g., Grossmann \& Varnum, 2015; Inglehart \& Baker, 2000) suggests that increases in socioeconomic development, disaster frequency, and pathogen prevalence would accompany increases in individualism. As shown in Table 2, these hypotheses were mostly supported: increases in socioeconomic development (SED), practices: $R^{2}{ }_{m}=.58$, values: $R^{2}{ }_{m}=.35$ and decreases in pathogen prevalence, practices: $R^{2}{ }_{m}=.03$, values: $R^{2}{ }_{m}=.02$, were linked to increases in individualism. Notably, increases in disaster frequency led to increases in individualistic practices but not values, practices: $R^{2}{ }_{m}=.09$, values: $R^{2}{ }_{m}=.01$. In addition, there was a significant interaction between climate and socioeconomic development for practices, $\Delta \mathrm{AIC}=7.30$, but not values, $\Delta \mathrm{AIC}=0.40(\Delta \mathrm{AIC}>2$ indicates a sizable difference between the models with and without an interaction term). Specifically, the harsher the climate, the more strongly SED was associated with shifts towards individualistic practices (see Figure 3). This finding is partially consistent with the climato-economic theory of cultural change (Van de Vliert, 2013). Recall that the theory predicts that in less developed countries, harsher climate would promote less individualism, whereas in more developed countries, harsher climate would promote more individualism. Here, we observe that in lower SED countries changes in climate were related to decreases in individualism, whereas in more developed SED countries they were not related.

Table 2.

Effect of Socio-Ecological Factors on Individualistic Practices and Values.

\begin{tabular}{|c|c|c|c|c|c|c|c|}
\hline \multicolumn{2}{|c|}{$\begin{array}{l}\text { Socioeconomic } \\
\text { Development }\end{array}$} & \multicolumn{2}{|c|}{ Disaster Frequency } & \multicolumn{2}{|c|}{ Pathogen Prevalence } & \multicolumn{2}{|c|}{$\begin{array}{c}\text { Climate x Socioeconomic } \\
\text { Development }\end{array}$} \\
\hline$B(S E)$ & $t(d f)$ & $B(S E)$ & $t$ & $B(S E)$ & $t$ & $B(S E)$ & $t$ \\
\hline 0.66 & 15.46 & 0.58 & 5.81 & -0.18 & -3.25 & 0.02 & 3.13 \\
\hline$(0.04) * * *$ & (181.22) & $(0.10)^{* * *}$ & (114.31) & $(0.05)^{* *}$ & $(116.22)$ & $(0.007)^{* *}$ & (181.79) \\
\hline 0.59 & 9.51 & 0.19 & 1.46 & -0.19 & -2.71 & 0.02 & 1.58 \\
\hline$(0.06) * * *$ & (188.64) & $(0.13)$ & $(178.85)$ & $(0.07)^{* *}$ & $(221.32)$ & $(0.01)$ & $(156.49)$ \\
\hline
\end{tabular}


Note: Estimates from a multi-level model analysis, with annual data nested within country data. The top row shows findings for individualistic practices; the bottom row shows those for individualistic values. We calculated grand means and standard errors based on all countries and years in the sample.

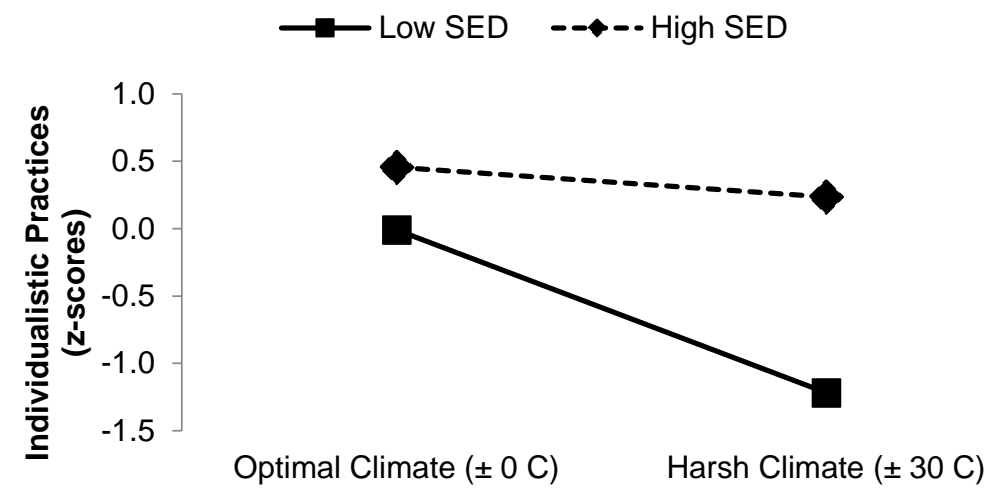

Fig. 3.

Effect of Effect of Climate Change (from Optimal to Harsh) and Socioeconomic Development (SED) on Change in Individualistic Practices. High/low SED plotted at the $25^{\text {th }} / 75^{\text {th }}$ percentiles of Change in SED.

Across these factors, socioeconomic development had the strongest effect; between $35 \%$ and $58 \%$ of the change in individualism over time can be attributed to shifts in socioeconomic development (almost four times as much as the next largest predictor). Looking more closely at individual measures of socioeconomic development, increases in the proportion of white-collar vs. agriculture jobs, practices: $R^{2}{ }_{m}=.42$, values: $R^{2}{ }_{m}=.42$, occupational prestige, practices: $R^{2}{ }_{m}$ $=.33$, values: $R^{2}{ }_{m}=.25$, educational attainment, practices: $R^{2}{ }_{m}=.60$, values: $R^{2}{ }_{m}=.46$, income, practices: $R^{2}{ }_{m}=.40$, values: $R^{2}{ }_{m}=.38$, were all associated with rises in individualism (see Table 3). Increases in urbanization was only associated with increases in practices, practices: $R^{2}{ }_{m}=.25$; we did not have enough data to examine the relationship for values. In summary, although all measures of income are strong correlates of cultural change, type of job, education, and income are particularly powerful factors. The effect of socioeconomic development also held when controlling for year, disaster frequency, pathogen prevalence, and climate. 
Table 3.

Socioeconomic Development Predictors of Individualistic Practices and Values.

\begin{tabular}{cccccccccc}
\hline \multicolumn{2}{c}{ White-Collar vs. } & \multicolumn{2}{c}{ Occupational Prestige } & \multicolumn{2}{c}{ Educational } & \multicolumn{2}{c}{ Income } & \multicolumn{2}{c}{ Urbanization } \\
Agriculture Jobs & \multicolumn{9}{c}{ Attainment } \\
$B(S E)$ & $t(d f)$ & $B(S E)$ & $t(d f)$ & $B(S E)$ & $t(d f)$ & $B(S E)$ & $t(d f)$ & $B(S E)$ & $t(d f)$ \\
\hline 1.22 & 9.81 & 0.19 & 8.45 & 1.16 & 16.09 & 0.69 & 13.15 & 1.52 & 6.44 \\
$(0.12)^{* * *}$ & $(148.55)$ & $(0.02)^{* * *}$ & $(155.81)$ & $(0.07)^{* * *}$ & $(179.73)$ & $(0.05)^{* * *}$ & $(158.58)$ & $(0.24)^{* * *}$ & $(119.00)$ \\
1.38 & 4.55 & 0.10 & 3.34 & 0.83 & 5.53 & 0.87 & 10.03 & -- & -- \\
$(0.30)^{* * *}$ & $(19.30)$ & $(0.03)^{* *}$ & $(25.68)$ & $(0.15)^{* * *}$ & $(27.28)$ & $(0.09)^{* * *}$ & $(182.74)$ & - & - \\
\hline
\end{tabular}

Note: Estimates from a multi-level model analysis, with annual data nested within country data. The top row shows results for individualistic practices; the bottom row shows results for individualistic values. We calculated grand means and standard errors based on all countries and years in the sample. There was not enough data to conduct MLM analyses for urbanization and values.

\section{Socioeconomic Development as a Mediator}

Although the MLM analyses reported above show a correlation between socio-ecological factors and individualism, they do not necessarily imply a causal relationship. Given that socioeconomic development was the only non-negligible correlate of individualism in our prior analyses, we focused on this factor for subsequent analyses of lagged effects and mediation (see Supplementary Analyses for findings with the other factors).

First, we looked at the lagged effects of socioeconomic development, as previous work has suggested that relationships between ecology and cultural change may occur at a lag (e.g., Grossmann \& Varnum, 2015). We expected changes in socioeconomic development to be associated with similar shifts in individualism 10 years later (i.e., a 10-year lead), suggesting a causal path from the former variable to the latter. We chose to lead the data by 10 years, since most census data is collected by the decade (we also found similar findings with shorter leads; see Supplementary Analyses). By leading the individualism data by 10 years, and running an MLM analysis, we found that changes in socioeconomic development resulted in subsequent shifts in individualistic practices, $B=0.59, S E=0.04, t(154.03)=13.55, p<.001, R^{2}{ }_{m}=.48$, and values, $B=0.46, S E=0.09, t(36.70)=5.27, p<.001, R^{2}{ }_{m}=.43$. 
Next, we tested whether socioeconomic development could explain the effect of time on individualism. Using the mediation package in R, we conducted mediation analyses in MLM with time predicting individualistic practices and values, both set 10 years later, with SED as a mediator (see Figure 4). The conditions for establishing mediation were met as the $95 \%$ confidence interval of the indirect effects did not include zero, practices: 95\% CI [0.01, 0.02], values: $95 \%$ CI [0.003, 0.01], suggesting that the rise of individualism was in part explained by an increase in socioeconomic development (see supplementary analysis for similar mediation results without a 10-year lead). Taken together, the lagged and mediation analyses lend support to a causal relationship between socioeconomic development and individualism.

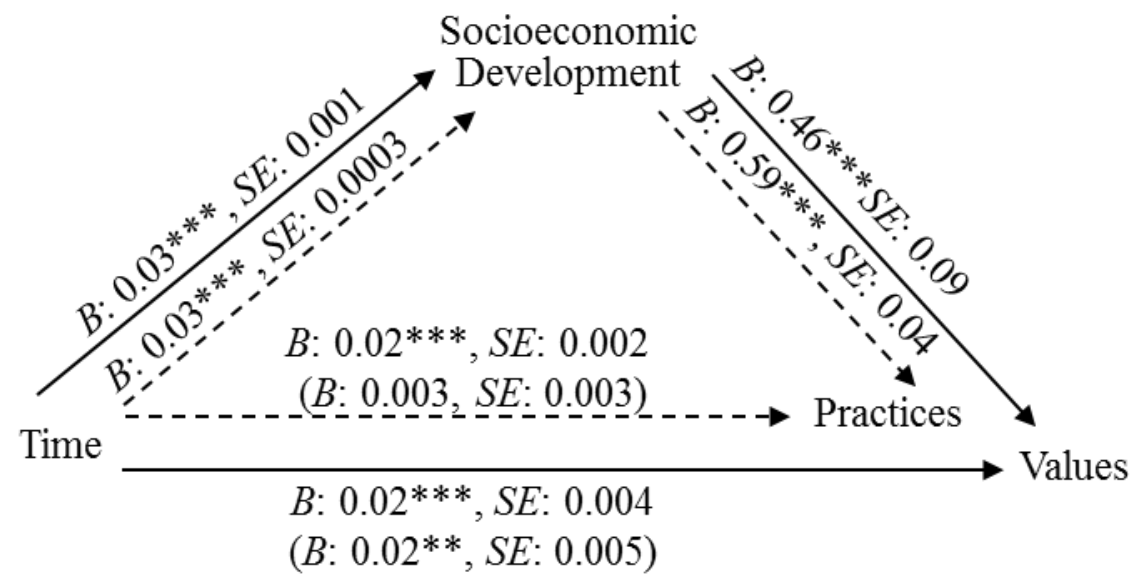

Fig. 4.

Indirect Effect of Time on Individualism (10-year Lead) through Socioeconomic Development. Unstandardized coefficients and standard errors are shown. The values in parentheses show the relationship between time and the individualism after controlling for Socioeconomic Development. $\uparrow p<.10, * p<.05, * * p<.01, * * * p<.001$.

\section{Discussion}

Is the rise of individualism a global phenomenon? Our analysis of data across 51 years and 77 countries suggests that the answer is yes. Thirty-four (out of 41) countries showed a substantial rise in individualist practices. Thirty-seven (out of 52) countries showed a similar rise on a subset of markers assessing individualist values. The IC change for practices and values 
were similar at around $12 \%$. Overall, these results show that a shift toward greater individualism is not confined to the developed world.

Increasing individualism appears to be linked to several previously theorized sources of cultural variation, including socioeconomic development, disaster frequency, pathogen prevalence, and climatic variations. Notably, the last three factors only affected individualistic practices, not values. Of these ecological dimensions, socioeconomic development emerged as the key predictor, explaining between 35 and $58 \%$ of the variance in IC-related change over time. Moreover, we found that changes in socioeconomic development mediated the effect of time on individualism, and increases in socioeconomic development preceded increases in individualism. Future research could examine how regional variations in these predictors might influence the rate of cultural change.

We observed a few exceptions to the global rise in individualism. Cameroon, Malawi, Malaysia, and Mali showed a decline in individualistic practices and Armenia, China, Croatia, Ukraine, and Uruguay showed a non-negligible decline in individualistic values. Also, several countries did not change much over time (see Supplementary Analyses). Consistent with the observation that socioeconomic development is driving the rise in individualism, most of these countries were among the lowest in socioeconomic development over the same time period. China is an exception to this pattern, showing a decrease in IC-practices and -values, respectively. Notably, China has a complex socioeconomic history, making it worthwhile to investigate them in more detail in future research.

In the current work cultural changes in IC are mostly viewed as evoked responses, whereby environmental cues or conditions lead to adaptive behavioral and psychological responses. However, cultural transmission likely plays a role in the phenomena we observed. 
Ecologically-driven changes in individual responses may also lead to changes in norms and institutions that reflect and promote an individualistic orientation. And consistent with the notion that cultural transmission is involved in cultural changes in IC, Newson and Richerson (2009) propose that close interaction with kin promotes social learning about reproductive fitness. They argue that the transmission of this information would encourage more traditional and collectivistic values. In this view, the rise of modern economies has led to greater contact with non-kin vs. kin; hence, individualism should increase. An important future direction in the study of cultural change will be integrating theory and research on cultural evolution, which tends to focus more on processes of cultural transmission, with work (such as the present study) on how specific ecological changes may lead to specific patterns of cultural change.

Before concluding, let us consider some caveats. First, the present work focused on the role of relatively proximal ecological factors for changes in individualism-collectivism. There are also several distal historical explanations that have been advanced to explain variations and potentially shifts in IC, including modes of subsistence (e.g., Talhelm et al., 2014) and migration to frontiers (Kitayama et al., 2010). Ecological factors might drive such trends or mediate the effects of such events on IC. A key future direction in studying cultural change will involve a theoretical or modelling-based (cf. Oishi \& Kesebir, 2012) integration of proximal and distal explanations. Further, though present research focused on overall shifts of common features of IC over time, some aspects of individualism may deviate from these general patterns (Hamamura, 2012; Kashima, 2014; Kitayama et al., 2010). Indeed, there is emerging evidence that IC may be more multifaceted than previously believed (Vignoles et al., 2016). Moreover, we had a limited number of data points available per country, and our analyses were constrained to linear models of change. With the prospect of greater availability of cross-temporal data, future 
work may explore more fine-grained models integrating social ecology and a multi-faceted IC construct, making the study of cultural change an exciting scientific endeavor in the years ahead. 


\section{Author Contributions:}

I.G. developed the study concept. All authors contributed to study design. Data analysis was conducted by H.S. under the supervision of I.G. H.S. and I.G. drafted the manuscript and M.V. provided critical revisions. All authors approved the final version of the manuscript for submission.

\section{Acknowledgements:}

We thank Sylvia Cheng, Jacklyn Koyama, and Reanne Howard for research assistance. Work on this manuscript was supported by the Insight grant \#435-2014-0685 from the Social Sciences and Humanities Research Council of Canada to Igor Grossmann. 


\section{References}

Deaton, A. (2008). Income, health, and well-being around the world : Evidence from the Gallup World Poll. Journal of Economic Perspectives, 22(2), 53-72.

Greenfield, P. M. (2009). Linking social change and developmental change: Shifting pathways of human development. Developmental Psychology, 45(2), 401-418. http://doi.org/10.1037/a0014726

Greenfield, P. M. (2013). The changing psychology of culture from 1800 through 2000. Psychological Science, 24, 1722-1731. http://doi.org/10.1177/0956797613479387

Grossmann, I., \& Na, J. (2014). Research in culture and psychology: Past lessons and future challenges. Wiley Interdisciplinary Reviews: Cognitive Science, 5, 1-14. http://doi.org/10.1002/wcs.1267

Grossmann, I., \& Varnum, M. E. W. (2015). Social structure, infectious diseases, disasters, secularism, and cultural change in America. Psychological Science, 26, 311-324. http://doi.org/10.1177/0956797614563765

Hamamura, T. (2012). Are cultures becoming individualistic? A cross-temporal comparison of Individualism-Collectivism in the United States and Japan. Personality and Social Psychology Review, 16(1), 3-24. http://doi.org/10.1177/1088868311411587

Hofstede, G. (2001). Culture's consequences: Comparing values, behaviors, institutions and organizations across nations (2nd ed.). Thousand Oaks, CA: Sage Publications. 
Hox, J. (2002). Multilevel analysis. 2002. Mahwah, NJ: Lawrence Erlbaum.

Inglehart, R. F., \& Baker, W. E. (2000). Modernization, cultural change, and the persistence of traditional values. American Sociological Review, 65(1), 19-51. http://doi.org/10.2307/2657288

Inglehart, R. F., \& Oyserman, D. (2004). Individualism, autonomy, self-expression: The human development syndrome. In H. Vinken, J. Soeters, \& P. Ester (Eds.), Comparing cultures: Dimensions of culture in a comparative perspective (pp. 76-96). Leiden, The Netherlands: Brill.

Kağıtçıbaşı, Ç. (2007). Family, self, and human development across cultures. Mahwah, NJ: Erlbaum.

Kashima, Y. (2014). How can you capture cultural dynamics? Frontiers in Psychology, 5, 1-16. http://doi.org/10.3389/fpsyg.2014.00995

Kashima, Y., \& Kashima, E. S. (2003). Individualism, GNP, climate, and pronoun drop: Is individualism determined by affluence and climate, or does language use play a role? Journal of Cross-Cultural Psychology, 34(1), 125-134. http://doi.org/10.1177/0022022102239159

Kitayama, S., Conway, L. G., Pietromonaco, P. R., Park, H., \& Plaut, V. C. (2010). Ethos of independence across regions in the United States: The production-adoption model of cultural change. The American Psychologist, 65(6), 559-574. http://doi.org/10.1037/a0020277 
Kraus, M. W., Piff, P. K., Mendoza-Denton, R., Rheinschmidt, M. L., \& Keltner, D. (2012).

Social class, solipsism, and contextualism: How the rich are different from the poor. Psychological Review, 119, 546-572. http://doi.org/10.1037/a0028756

Markus, H. R., \& Kitayama, S. (1991). Culture and the self: Implications for cognition, emotion, and motivation. Psychological Review, 98(2), 224-253.

Morling, B., \& Lamoreaux, M. (2008). Measuring culture outside the head: A meta-analysis of individualism-collectivism in cultural products. Personality and Social Psychology Review, 12(3), 199-221. http://doi.org/10.1177/1088868308318260

Morris, M. W., Chiu, C., \& Liu, Z. (2015). Polycultural psychology. Annual Review of Psychology, 66, 631-659. http://doi.org/10.1146/annurev-psych-010814-015001

Murray, D. R., Trudeau, R., \& Schaller, M. (2011). On the origins of cultural differences in conformity: Four tests of the pathogen prevalence hypothesis. Personality \& Social Psychology Bulletin, 37(3), 318-329. http://doi.org/10.1177/0146167210394451

Nakagawa, S., \& Schielzeth, H. (2013). A general and simple method for obtaining R2 from generalized linear mixed-effects models. Methods in Ecology and Evolution, 4(2), 133-142. http://doi.org/10.1111/j.2041-210x.2012.00261.x

Naroll, R. (1983). The moral order. Beverly Hills, CA: Sage.

Newson, L., \& Richerson, P. J. (2009). Why Do People Become Modern? A Darwinian Explanation. Population and Development Review, 35(1), 117-158. http://doi.org/10.1111/j.1728-4457.2009.00263.x 
Ogihara, Y., Fujita, H., Tominaga, H., Ishigaki, S., Kashimoto, T., Takahashi, A., ... Uchida, Y. (2015). Are common names becoming less common? The rise in uniqueness and individualism in Japan. Frontiers in Psychology, 6(1490), 1-14. http://doi.org/10.3389/fpsyg.2015.01490

Oishi, S., \& Graham, J. (2010). Social Ecology: Lost and Found in Psychological Science. Perspectives on Psychological Science, 5(4), 356-377. http://doi.org/10.1177/1745691610374588

Oishi, S., \& Kesebir, S. (2012). Optimal social-networking strategy is a function of socioeconomic conditions. Psychological Science, 23(12), 1542-1548. http://doi.org/10.1177/0956797612446708

Schaller, M., \& Park, J. H. (2011). The behavioral immune system (and why it matters). Current Directions in Psychological Science, 20(2), 99-103. http://doi.org/10.1177/0963721411402596

Schimmack, U., Oishi, S., \& Diener, E. (2005). Individualism: a valid and important dimension of cultural differences between nations. Personality and Social Psychology Review, 9(1), 17-31. http://doi.org/10.1207/s15327957pspr0901_2

Talhelm, T., Zhang, X., Oishi, S., Shimin, C., Duan, D., Lan, X., \& Kitayama, S. (2014). Largescale psychological differences within China explained by rice versus wheat agriculture. Science, 344(6184), 603-608. http://doi.org/10.1126/science.1246850 
Thornhill, R., \& Fincher, C. L. (2014). The parasite-stress theory of values and sociality. New York, NY: Springer.

Triandis, H. C. (1995). Individualism and collectivism: New directions in social psychology. Boulder, CO: Westview Press.

Triandis, H. C. (2009). Ecological determinants of cultural variations. In R. S. Wyer, C. Chiu, Y. Hong, \& D. Cohen (Eds.), Understanding culture: Theory, research and applications (pp. 189-210). New York, NY: Psychology Press.

Twenge, J. M., Dawson, L., \& Campbell, W. K. (2016). Still standing out: Children's names in the United States during the Great Recession and correlations with economic indicators. Journal of Applied Social Psychology, 46, 663-670. http://doi.org/10.1111/jasp.12409

Twenge, J. M., Campbell, W. K., \& Gentile, B. (2012). Generational increases in agentic selfevaluations among American college students, 1966-2009. Self and Identity, 11, 409-427. http://doi.org/10.1080/15298868.2011.576820

Van de Vliert, E. (2013). Climato-economic habitats support patterns of human needs, stresses, and freedoms. The Behavioral and Brain Sciences, 36(5), 465-80. http://doi.org/10.1017/S0140525X12002828

Vandello, J. A., \& Cohen, D. (1999). Patterns of individualism and collectivism across the United States. Journal of Personality and Social Psychology, 77(2), 279-292. http://doi.org/10.1037//0022-3514.77.2.279 
Varnum, M. E. W., Grossmann, I., Kitayama, S., \& Nisbett, R. E. (2010). The origin of cultural differences in cognition: Evidence for the social orientation hypothesis. Current Directions in Psychological Science, 19(1), 9-13. http://doi.org/10.1177/0963721409359301

Vignoles, V. L., Owe, E., Becker, M., Smith, P. B., Easterbrook, M. J., Brown, R., ... Bond, M. H. (2016). Beyond the "east-west" dichotomy: Global variation in cultural models of selfhood. Journal of Experimental Psychology. General, 145(8), 966-1000. http://doi.org/10.1037/xge0000175

Wachtel, P. L. (1968). Anxiety, attention, and coping with threat. Journal of Abnormal Psychology, 73(2), 137-143. http://doi.org/10.1037/h0020118

Yamagishi, T., Hashimoto, H., Li, Y., \& Schug, J. (2012). Stadtluft macht frei (City air brings freedom). Journal of Cross-Cultural Psychology, 43, 38-45. http://doi.org/10.1177/0022022111415407

Yu, F., Peng, T., Peng, K., Tang, S., Chen, C. S., Qian, X., ... Chai, F. (2016). Cultural value shifting in pronoun use. Journal of Cross-Cultural Psychology, 47(2): 310-316. http://doi.org/ 10.1177/0022022115619230

Zeng, R., \& Greenfield, P. M. (2015). Cultural evolution over the last 40 years in China: Using the Google Ngram Viewer to study implications of social and political change for cultural values. International Journal of Psychology, 50, 47-55. http://doi.org/10.1002/ijop.12125 